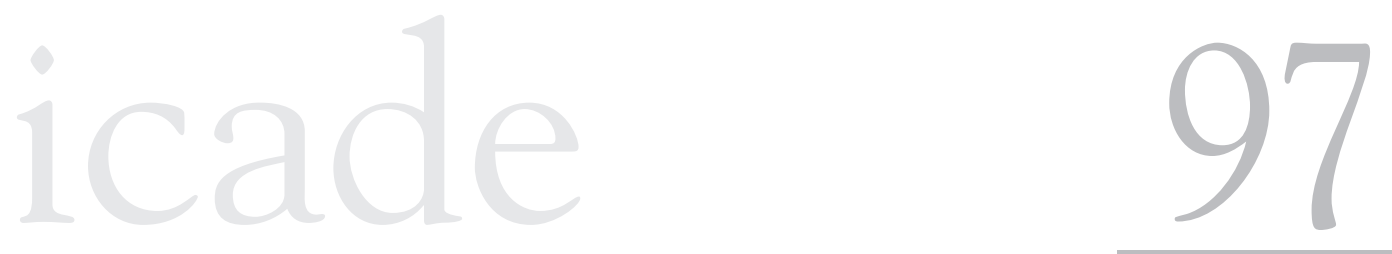

ENERO | ABRIL [2016]

Miscelánea 



\title{
LA ADMINISTRACIÓN DE LA AGROINDUSTRIA AZUCARERA EN LA CUBA COLONIAL: UN SISTEMA PRECURSOR DEL “SCIENTIFIC MANAGEMENT”
}

\author{
Autor: Santiago Garrido Buj ${ }^{1}$ \\ Catedrático de Organización de Empresas de la UNED
}

\section{Resumen}

Los historiadores del moderno management vinculan la aparición del mismo a las obras de Taylor y Fayol y al nacimiento de las grandes corporaciones del capitalismo industrial, en especial los ferrocarriles. Las plantaciones esclavistas han sido deliberadamente omitidas de este "amanecer" de la gestión científica. Sin embargo su coincidencia e incluso prelación en el tiempo y sus métodos de gestión, unidos a la clara separación entre propietarios y gestores, confieren a aquellas el carácter de auténticas precursoras de la gestión científica.

\footnotetext{
${ }^{1}$ sgarrido@cee.uned.es
} 
Este artículo trata de demostrar cómo los ingenios azucareros cubanos de la segunda mitad del siglo XIX son un claro ejemplo de gestión racional y eficiente que avala lo apuntado en el párrafo anterior.

Palabras clave: plantaciones esclavistas; gestión científica; gestión de empresas; Cuba; azúcar; ingenios azucareros; siglo XIX.

\title{
Administration of sugar industry in colonial Cuba: a precursor system of scientific management
}

\begin{abstract}
Historians of modern management link occurrence of this to the works of Taylor and Fayol and the birth of the great corporations of industrial capitalism, especially railways. The slave plantations have been deliberately omitted from this "dawn" of scientific management, however its coincidence and even priority in time and management methods, coupled with the clear separation between owners and managers give to those authentic character precursors scientific management.

This paper attempts to show how the Cuban sugar mills in the second half of the nineteenth century are a clear example of rational and efficient management endorses it pointed in the paragraph above.
\end{abstract}

Key words: slave plantations; scientific management; business management; Cuba; sugar; sugar mills; nineteenth century.

\section{LA ADMINISTRACIÓN O GESTIÓN DE LOS INGENIOS AZUCA- REROS CUBANOS CON MANO DE OBRA FORZADA}

En las economías coloniales pre industriales como la del azúcar, que agrupan campo y fábrica, la necesidad de coordinar tareas, el equilibrado de líneas de producción y todo ello con el manejo de una mano de obra sui generis, hizo necesario contar con un elemento autónomo como es la función de administración, debiendo desarrollarse asimismo una contabilidad y un cálculo de costes para poder funcionar de una forma óptima, coordinando el campo con la fábrica, y ambos con la demanda, y con las consabidas restricciones económicas. 
Curiosamente esta necesidad de un elemento autónomo, como es la administración, para coordinar otras tareas y funciones de las plantaciones, ha sido frecuentemente pasada por alto por los estudiosos de la historia del management, es más, existen en la literatura anglosajona artículos negando la utilización del management en las plantaciones y manufacturas ligadas a la esclavitud ${ }^{2}$. El desagrado que la esclavitud produce en las mentes de épocas posteriores a su existencia, hace que se olviden otros aspectos como el uso de técnicas de gestión racionales, que sólo pueden ser descritas y analizadas desde una óptica aséptica y alejada de connotaciones morales. En sentido contrario hemos encontrado también unas limitadas referencias a la administración de las haciendas esclavistas relacionándolas con el management científico (Aufhauser, 1973)³. Sin embargo un estudio más exhaustivo de las prácticas esclavistas pone de manifiesto que dichas explotaciones se manejaban con criterios de eficiencia y con fórmulas próximas a los principios del Taylorismo o dirección científica del trabajo, pudiendo incluso afirmarse que las plantaciones esclavistas de la segunda mitad del siglo XIX fueron precursoras y base del moderno pensamiento sobre gestión y que sus gestores actuaron como auténticos managers en el sentido moderno del término.

La realidad es que resulta difícil explicar los altos niveles de productividad de algunas economías de plantación del siglo XVIII y XIX, sin recurrir como factor explicativo a un, cuando menos acertado, sistema de gestión. La asociación entre productividad y mano de obra esclava siempre ha sido negada entendiéndose que eran dos factores incompatibles, aunque la dura realidad por una parte y los estudios de los cliómetras como Fogel y Engerman (1981) por otra muestran a las claras lo contrario. Quizás habría que pensar que si bien la mano de obra esclava en modo alguno se encontraba ligada a la consecución de beneficios en cuanto a percepción de una parte de los mismos, los esclavos sí veían sus vidas, en el sentido de "calidad de vida", ligadas a la producción. La elección de la brutalidad por parte de los patronos o administradores no parece que permitiese constatar unos rendimientos superiores a los de las explotaciones que optaban por un trato más benigno.

En principio los propietarios de plantaciones concentraban su esfuerzo en la exportación de mercancía y más concretamente, en el caso del azúcar, buscaban el contar con plantaciones de gran tamaño en términos de superficie de cultivo, fuerza de trabajo y producto generado. Por contra las instalaciones europeas de

\footnotetext{
${ }^{2}$ En tal sentido puede verse por ejemplo el artículo The Denial of Slavery in Management Studies de Bill Cooke (Cooke, 2003).

${ }^{3}$ El Scientific Management, también denominado Taylorismo es una teoría de gestión desarrollada por F. W. Taylor (Taylor, 1911) que analiza y sintetiza los flujos de trabajo. Su principal objetivo es mejorar la eficiencia económica, en especial la productividad del trabajo. Fue uno de los primeros intentos de aplicar la ciencia a la ingeniería de procesos y al management o gestión.
} 


\section{Santiago Garrido Buj}

dicha época de advenimiento de la revolución industrial contaban más con los avances tecnológicos y las ventajas que tecnologías, como la máquina del vapor, podían ofrecerles, que con la mano de obra, por otra parte también en condiciones de semi-esclavitud. Quizás como algunos dicen en las economías esclavistas se optó por obviar las ventajas de la tecnología con una explotación más intensiva de la mano de obra. No obstante, esto último está por demostrar, máxime cuando las ventajas de la tecnología fueron prácticamente conocidas de forma cuasi inmediata y a la vez que en Europa, en el área del Caribe, y en la medida de lo posible y de las posibilidades de financiación, incorporadas a los sistemas productivos.

Solamente un profundo cambio en los modos de producción y fabricación ligados a una conjunción de factores, como son la mejora de los rendimientos de la tierra, la potencialidad de las casas de molienda y calderas, y la mejora de los sistemas de depuración del azúcar, llevaron a convertir en un factor crítico las economías de escala derivadas de la gran producción, lo que en nuestra opinión fue el principal factor que rompió el modelo de negocio anterior de pequeñas y medianas explotaciones basadas en la mano de obra propia, forzada e intensiva, para dar paso al colonato; al reparto de la tierra en pequeñas o medianas explotaciones autónomas y de naturaleza exclusivamente agraria, que suministraban su producto a los nuevos macro ingenios, y también, conjuntamente con ello, a la diversificación de riesgos y a los grandes centrales azucareros.

Este tipo de explotaciones que conforman toda una red (network) conectada inicialmente con pequeños proveedores de todo tipo de commodities al servicio del demandante cuasi único que es el ingenio y con los mercados exteriores a través de los agentes comerciales, tienen una característica singularizante y definitoria que es la propiedad de la mano de obra, pudiéndose decir que es la esclavitud la que hace ricos a los "plantadores" por ser no solamente el único elemento diferenciador de otras explotaciones, ya sean agrícolas o de manufactura, sino también el factor estratégico, coyuntural y crítico necesario para dicho modelo de negocio y su supervivencia. Casi nos atreveríamos a decir que el modelo de negocio de la industria azucarera cubana de los años 50 a 80 del siglo XIX sólo tiene sentido si se cuenta con mano de obra esclava y no es posible su repetición sin aquella.

Cuando se observa la evolución de los ingenios azucareros en los siglos XVIII y XIX puede constatarse una sutil y lenta transición del "empresario-propietario" a la progresiva separación de las tareas de administración de las de propiedad. Se diría que el crecimiento lento pero continuado del tamaño de las explotaciones con la consiguiente complejidad de las tareas, debido precisamente al manejo de más factores y en mayor cantidad, llevaban inexorablemente a una especialización del trabajo de gestión que en muchos casos el hacendado dejaba en manos de terce- 
ros. Se produce así con la aparición de los mayordomos ${ }^{4}$, como máxima figura en la gestión del ingenio al servicio de los propietarios en muchos casos absentistas, el fenómeno que también conocemos en la economía en general de evolución o transición de la figura del empresario-dueño a la separación de ambas figuras.

Alfred Chandler en su historia de la empresa americana (Chandler, 1977) da poca importancia al papel de las explotaciones azucareras del Sur de los EE. UU. en cuanto a su contribución a la formación de una dirección o gestión de los negocios más moderna y evolucionada, siendo pocos los trabajos como el R. Keith Aufhauser (1973) que inciden en cómo la división del trabajo y la especialización de tareas en los conglomerados o explotaciones azucareras con una gran estructuración de tareas que era necesario coordinar y disciplinar, convierten a dichas explotaciones en precursoras de lo que después se llamó la dirección científica del trabajo ${ }^{5}$.

Considera igualmente Chandler que la función del management hay que vincularla a la aparición de las grandes compañías del ferrocarril (Chandler, 1965) en razón de las importantes economías de escala que podían lograrse con una adecuada gestión que comenzaba a separarse de la propiedad como función ${ }^{6}$. En su opinión las explotaciones esclavistas pese a ofrecer cierta complejidad en su gestión, no pueden considerarse precursoras del moderno management toda vez que no hubo una efectiva separación entre propietarios y gestores; tampoco tuvieron un tamaño que pudiese considerarse grande, y el trabajo de los supervisores se limitaba a poco más que el control de la mano de obra esclava. No obstante y a diferencia de las explotaciones del sur de EE. UU., en las que basaba sus opiniones, en el Caribe el tamaño de las explotaciones era bastante mayor, y sí existía separación entre propietarios absentistas y gestores. Igualmente la necesaria coordinación entre las labores agrícolas y la manufactura requerían de una coordinación y planificación de tareas sumamente minuciosa y compleja.

En opinión del autor, y sin pretender convertir en un aserto formal y universal lo que se va a decir, tanto el hacendado, en el caso de llevar personalmente la

${ }^{4}$ El mayordomo en la terminología de la época equivale al actual administrador. El diccionario de la RAE lo define como "Criado principal a cuyo cargo está el gobierno económico de una casa o hacienda" y, en su cuarta acepción, define al mayordomo como "Agente principal del propietario, arrendatario o administrador de una hacienda".

${ }^{5}$ Chandler considera que la empresa moderna y la figura del empresario surgieron por su capacidad de lograr la eficiencia a través de la coordinación debido a que tenían que coordinar un sistema cada vez más complejo e interdependiente, consolidándose cuando la coordinación administrativa fue mejor que los mecanismos de mercado en la mejora de la productividad y reducción de los costes. La jerarquía administrativa se convirtió entonces en un requisito previo para la consecución de ventajas por la coordinación de varias unidades dentro de una misma empresa. Para este autor lo que define a la empresa moderna es su multifuncionalidad, tamaño y separación entre propiedad y gerencia que se configura como un factor diferenciado y esencial.

${ }^{6}$ Para conocer a fondo el concepto chandleriano de empresa moderna puede verse también su obra Scale and Scope. The Dynamics of Industrial Capitalism (Chandler, 1990). 
explotación, como casi siempre el mayordomo de la misma (que probablemente sería comparable a la figura en las Sugar Islands del Attorney y el Overseer ${ }^{7}$ ) presentan un perfil como gestores altamente especializados, donde quizás la asunción de un elevado número de funciones (en muchos casos excesivo) les convierte en unos "hombres orquesta" de la gestión de las plantaciones. Así la función de mayordomía, (término, éste último, por otro lado también usado en la metrópoli durante el siglo XIX), suponía la asunción de un sinnúmero de tareas como son las relativas al personal, tanto en su selección, formación y adecuación al puesto de trabajo (a la que se unía todo el control de las tareas de supervisión y represión inherentes a la mano de obra forzada). Igualmente solían ser los responsables de las construcciones participando incluso en su diseño y sobre todo gestionando su mantenimiento. En tercer lugar les competían todas las labores del trabajo en la tierra que en ocasiones podían incluso incrementarse con la selección de nuevos terrenos y también con la elección de los momentos óptimos de siembra y recolección. Eran además en muchas ocasiones los contables y los directores financieros de las firmas, encargándose también de todo lo referente al trading y relaciones con los agentes tanto locales como de la metrópoli o de otros mercados. Asumían igualmente las funciones de predicción y de planificación y la búsqueda y selección de las subcontratas y en definitiva toda la gestión y mantenimiento de la totalidad de los activos (bienes, personas, animales...) . $^{8}$.

La organización de los recursos humanos de un ingenio azucarero era, obviamente, de carácter piramidal, en la cúspide, tal y como muestra el Figura 1, se encontraba el propietario o hacendado que como ya se ha comentado podía desarrollar o no tareas de dirección. De hecho existían hacendados que vivían en la metrópoli frente a otros que lo hacían en la capital, en este caso La Habana, o incluso en el propio ingenio azucarero pero sin dedicarse a las tareas propias del negocio. Por el contrario otros hacendados, sobre todo en las explotaciones de menor tamaño, ejercían directamente todas o parte de las funciones que habitualmente estaban destinadas al administrador.

El administrador del ingenio era la figura clave del mismo, era el auténtico manager que realizaba la coordinación de todas las tareas y funciones. Del mismo dependían todos los trabajadores del ingenio incluidos aquellos que realizaban

${ }^{7}$ Sobre dichas figuras en el caribe inglés véase la obra de Higman Plantation Jamaica 1750-1810 (Higman, 2005).

${ }^{8}$ En el Caribe azucarero y/o plantacionista conviven al menos dos modelos de propietario-gestor, el del caribe inglés en el que el propietario vive en la Metrópoli y delega en un gerente la totalidad de la actividad, y el cubano donde el propietario generalmente vive en la capital, aunque acude temporalmente al ingenio, sobre todo en la época de la zafra, delegando también en un administrador, y en parte en los refaccionistas y comerciantes financiadores y compradores del producto final.

Cabría hablar de un tercer modelo que se correspondería con las postrimerías del caribe francés, en el que el propietario ausente comparte los resultados con el gestor o administrador local (sobre éste particular puede verse también la obra colectiva Economie de l'esclavage colonial (Célimène \& Legris, 2005). 
tareas de forma más o menos independiente (trabajos contratados) e incluso el servicio doméstico de la casa del hacendado y obviamente los servicios de vigilancia.

\section{Figura 1. Jerarquía de personal en los ingenios azucareros}

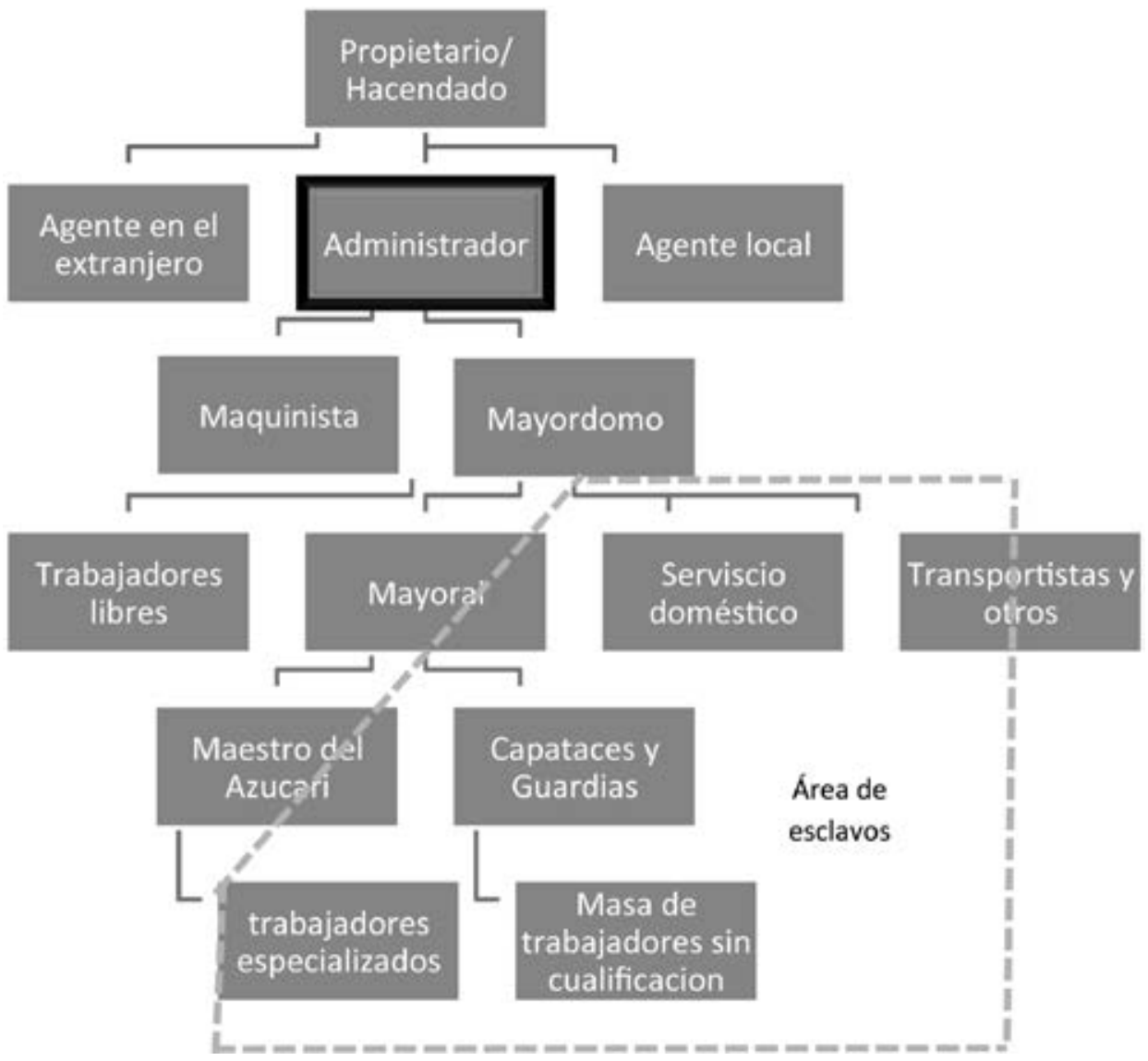

Fuente: elaboración propia.

En algunos casos al mismo nivel que el administrador, cuando la relación con aquellos la realizaba el propietario, se encontraban los factores o agentes que movía la mercancía en los mercados y que contrataban la producción. Éstos podían ser locales o bien estar ubicados en el extranjero (en la metrópoli o en otras plazas comerciales) y eran los encargados de vender la producción. La venta de la producción conllevaba en ocasiones su vinculación al proceso de financiamiento del ingenio, de tal manera que el largo ciclo productivo (un año) podía ser costeado 


\section{Santiago Garrido Buj}

por los compradores de la producción y también por los meros agentes intermediarios. En este sentido puede verse por ejemplo el trabajo de Roland T. Ely sobre los comerciantes cubanos en el siglo XIX (Ely, 1961).

En el escalón siguiente se encontraba el mayordomo 9 que dependía directamente del administrador y cuyas tareas estaban más directamente relacionadas con aspectos tales como los inventarios o la contabilidad. En sus funciones podían ser ayudados por algunas personas con conocimientos específicos ya fuesen estos trabajadores libres o mano de obra forzada.

Por debajo del mayordomo se encontraba el mayoral o persona encargada directamente de la mano de obra y responsable de su rendimiento y algunos otros trabajadores que eran independientes a la explotación, tales como trabajadores libres que realizaban tareas de forma autónoma y bajo contrato como pudieran ser carpinteros o transportistas (en algunos casos sobre todo en los últimos tiempos también cabría incluir a los colonos independientes que podían aportar carretadas de caña o de leña al ingenio). Igualmente se encontraban en este escalón, ligeramente superior al de la masa de trabajadores del ingenio el personal dedicado al servicio doméstico en las casas de la plantación y también aquellos que realizaban tareas relacionadas con el exterior tales como transportistas u otras tareas similares.

Por debajo del mayoral se encontraban capataces y guardias, y en muchos casos, el denominado "maestro del azúcar" quien como trabajador especializado asumía el control de la calidad del azúcar procesado en base a sus conocimientos. Dicho trabajador podía ser un hombre libre o por el contrario pertenecer a la dotación de esclavos del ingenio y haber aprendido el oficio sobre la base de la experiencia con maestros anteriores.

Dependiendo del maestro del azúcar podía haber igualmente una masa de trabajadores especializados en las tareas de destilación y refinado del azúcar, generalmente esclavos, sometidos al mismo régimen que el resto de la mano de obra forzada de la plantación.

La pirámide jerárquica de trabajadores del ingenio se completaba con la gran masa de trabajadores no especializados que realizaban tanto tareas agrícolas como de manufactura, ya fuera en la casa de molienda como en la de purga o en tareas de transporte y almacenamiento.

Hemos incluido en esta jerarquía el trabajo del denominado "maquinista", persona que aparece en los ingenios azucareros con el avance de la mecanización y cuyo trabajo consistía en la puesta. Y mantenimiento de la maquinaria del mismo. Por lo general se trataba de profesionales libres procedentes de otros países, bien de Europa bien de los EE. UU., con conocimientos de ingeniería y mecánica

\footnotetext{
${ }^{9}$ En las pequeñas explotaciones ambas figuras tendían a confundirse e incluso a ser realizadas por una sola persona.
} 
y que con el tiempo pasaron a ser un elemento clave de la fase de transformación del azúcar con el aumento de la mecanización del proceso. Dada la temporalidad de este trabajo los denominados maquinistas o ingenieros solamente residían por lo general en la isla los seis meses de duración de la zafra.

Las tareas de gestión de un ingenio constituían una profesión especializada y singular que requería de unos conocimientos amplios, tanto sobre los modos de producción de azúcar en economías esclavistas de plantación, como de los posibles suministradores de factores productivos, y financiadores del ciclo de producción. Además hacía falta tener conocimientos específicos de gestión en general, constituyendo todo ello un "oficio" que era independiente del ingenio en el que se trabajaba y que posibilitaba los cambios de trabajo de los administradores de unos a otros Ingenios. De esta independencia de la figura del mayordomo del ingenio y su posible trasvase, dan buena fe los numerosos casos de Ingenios embargados y el nombramiento de administradores judiciales especializados al respecto.

La lista enunciada en el párrafo anterior podría completarse con muchas más tareas pudiéndose decir que el administrador de un ingenio era lo que el empresario-propietario en las pequeñas industrias y explotaciones capitalistas, pero en este caso gestionando unos complejos agroindustriales de tamaño mediano y de singular complejidad. Pudiera igualmente decirse que al igual que en muchos escritos académicos se vincula el nacimiento de la figura del manager profesional a la construcción de los ferrocarriles en el comienzo de la era industrial. En nuestra opinión, los mayordomos ${ }^{10}$ de ingenios azucareros en la segunda mitad del siglo XIX bien pudieran ser también considerados como precursores del moderno manager ${ }^{11}$ desde una óptica científica.

La moderna concepción del management pasa por la división entre propiedad y dirección ${ }^{12}$ así como por la división del trabajo. Entendemos que estos dos conceptos están básicamente contenidos en las explotaciones más características de la producción azucarera cubana, sobre todo de la segunda mitad del siglo XIX, pudiéndose hablar perfectamente de un trabajo diferenciado como administrador

\footnotetext{
${ }^{10}$ Se excluye a los hacendados y gestores de sus propias explotaciones por unir la función de gestor a la de dueño.

${ }^{11} \mathrm{El}$ mayordomo es la cabeza de una jerarquía u organigrama del ingenio que conecta por arriba con el propietario más o menos absentista, en paralelo con los agentes o intermediarios en el trading y con los refaccionistas, teniendo por debajo a mayorales y capataces y también a los responsables de las cubren sus contratas como pueden ser los carreteros, boyeros, carpinteros y otra mano de obra libre pero vinculada a la explotación. Por último y en la base de la pirámide se encontraría el conjunto de la mano de obra esclava tanto con destino en el campo como en la casa de calderas y en la de purga y también en el servicio doméstico, de enfermería etcétera.

${ }^{12}$ Curiosamente lo que en Europa y en general en todo el mundo industrial se considera un logro en el avance de los modos de gestión al hablarse de la diferenciación entre propiedad y dirección, por el contrario en muchos trabajos referidos a la economía caribeña de las plantaciones del siglo XIX se emplea idéntico argumento en sentido justamente contrario, esto es, se dice que unos propietarios absentistas eran una de las razones más importantes para la falta de progreso y evolución de las explotaciones esclavistas.
} 
de los ingenios y que se constituye en el agente intermediario entre el capitalista y la fuerza de trabajo de la empresa por él creada.

Hasta los años 30 del siglo XX no aparece una teoría suficientemente formalizada, coherente y potente acerca del papel del gestor o ejecutivo. Es con la teoría de los costes de transacción o si prefiere con la denominada economía institucional, cuando dicho concepto se formaliza ${ }^{13}$; sin embargo, cabe decir que todos los conceptos apuntados pueden perfectamente encontrarse en las explotaciones agro industriales productoras de azúcar en economías de plantación.

En las economías de plantación azucareras, los factores clave de incertidumbre se generaban alrededor del output o cantidad producida que como en toda explotación agraria dependía de factores climáticos y del precio final del producto, que a su vez estaba controlado por los agentes intermediarios. Junto a estos riesgos estaban los de eventuales problemas en la plantación o en la parte manufacturera, derivados de incendios o simples roturas del aparataje mecánico transformador. Todos estos factores eran los que junto y en primer lugar con la mano de obra era necesario que el gestor coordinara y dirigiera.

La dirección, planificación, organización y control de los ingenios azucareros era compleja. Tomadas las tres decisiones fundamentales o constitutivas, como eran el tipo de cultivo al que dedicarse y consecuentemente la elección de la tierra más adecuada; el tamaño de la explotación que pudiera generar rendimientos óptimos, y por último el tipo o forma de gestión, se pasaba a las decisiones del día a día, necesitándose coordinar los inputs a comprar o importar del extranjero con las necesidades, así como coordinar el personal y la relación entre el producto agrario y la capacidad de producción, y también equilibrar las líneas de generación del producto. La complejidad de estos procesos en explotaciones cada vez mayores requería de un cuidadoso y detallado estudio y control que permitiese llevar a buen término la empresa.

No se debe olvidar lo dicho dos párrafos más arriba cuando se ha hecho referencia, a que dos de los elementos de incertidumbre más importantes de esta industria eran la cantidad de caña conseguida en cada cosecha y el desconocimiento de los precios finales de la producción en los mercados de venta.

\footnotetext{
${ }^{13}$ Para dicha escuela de pensamiento que cabe asociar con los premios nobel Coase y Williamson y que supone una superación de la teoría neoclásica en la que se suponía la existencia de una información perfecta y del mecanismo del mercado como elemento básico y regulador de la actividad y resultados empresariales, la nueva teoría habla de los posibles mecanismos coordinadores de la actividad empresarial alternativos al sistema de precios como algo exógeno y de naturaleza interna como es el sistema organizativo, siendo la existencia de costos de transacción el elemento básico a tener en cuenta para organizar las transacciones a menor costo para la empresa y con ventajas sobre el logrado simplemente por el mercado. La empresa se considera así una forma de organización y el empresario cobra el papel de negociador en unos mercados complejos, con dispersión de precios, diferencias en las calidades y sobre todo con una fuerte interacción, incertidumbre económica, todo ello supuesta la racionalidad limitada del ser humano a la hora de tomar decisiones sobre qué hacer.
} 
Para tratar de paliar dicha incertidumbre el hacendado sólo contaba con la búsqueda de mecanismos que en alguna medida pudiesen asegurar el resultado final, y esto pasaba en una época en que no existían mercados de futuros organizados ni compañías de seguros dedicadas a este mundo agroindustrial, por la vinculación de la fabricación y sus resultados a la financiación del sistema. Así mediante la involucración de los financieros, acreedores e incluso compradores, en el proceso productivo los problemas derivados de una baja producción o de cambios negativos en los precios finales del producto eran soportados por todas las partes.

El trabajo del manager o gestor de un ingenio suponía gestionar en suma el riesgo e incertidumbre del negocio, un complejo agroindustrial sofisticado, mezclado con un brutal sistema de explotación de la mano de obra, y todo ello en una época sin la posibilidad del aseguramiento de muchos de los aspectos de la producción (seguros de cosechas, mercados de futuros, ...). Había que controlar los procesos y asumir los cambios debidos a riesgos tales como la climatología, incluidas las tormentas y tifones, los incendios, la roturas de la maquinaria y la dificultad de predecir los precios dado el largo período de producción y el pronto deterioro de la materia (era inusual que el producto se almacenara en espera de una negociación beneficiosa, habida cuenta de su carácter de producto perecedero y las malas condiciones de almacenamiento de la época), todo ello unido a averías técnicas o fallos energéticos por escasez o falta de combustible.

Solamente era asegurable el producto una vez que salía para su venta a través de seguros y fletes del transporte. Todos los riesgos anteriores debían ser calculados, reducidos y evaluados por los administradores.

El singular sistema de financiación de los ingenios azucareros cubanos en el que los refaccionistas y agentes comerciales aportaban su dinero al proceso en espera de cobrarse con los resultados de la producción, convertía a estos en partícipes en los riesgos, es más, en el caso de repetidos problemas en la producción o de bajada continuada en los precios, quienes estaban financiando al ingenio no tenían otra solución que esperar a cobrar su rendimientos o utilidades, pero sin dejar que el complejo agroindustrial perdiera su potencialidad, esto es, se hacía necesario seguir financiando el complejo para potencialmente recuperar lo invertido en épocas anteriores.

El complejo agroindustrial azucarero cubano es en este sentido peculiar, pues la inversión fundamental en infraestructuras y desde luego todo el capital circulante o de trabajo solía estar aportado por terceros. De tal manera esto era así, que muchas veces el hacendado sólo contaba como propios con la tierra -factor inicialmente extremadamente barato en la Isla- y con la mano de obra esclava, factores ambos que además no eran embargables, con lo cual el peso fundamental de la asunción de riesgos lo corrían quienes financiaban, intermediaban y pos- 


\section{Santiago Garrido Buj}

teriormente vendían la producción. Este sistema nos parece altamente singular, toda vez que sólo se suelen ver este tipo de relaciones producción-financiación en pequeños negocios promovidos o incentivados por quienes finalmente compran el producto para venderlo previa transformación o no. No suelen verse ejemplos de este tipo con instalaciones y explotaciones del tamaño de los ingenios azucareros.

El trabajo de José Antonio Piqueras acerca de la abolición de la esclavitud y el cambio en la industria azucarera denominado El capital emancipado: esclavitud, industria azucarera y abolición en Cuba (2002) es uno de los pocos trabajos que he encontrado en el que se adopta una óptica más o menos cercana a la Organización de empresas a la hora de analizar la industria azucarera en la Cuba de finales del siglo XIX. Aunque no estamos totalmente de acuerdo con sus conclusiones, puesto que a diferencia de él, sí creemos que existían cálculos más o menos precisos de rendimientos y costes por parte de muchos hacendados y también de quienes los financiaban, creemos que son de interés sus conclusiones.

Afirma el autor que el final de la esclavitud supuso una descapitalización de los Ingenios azucareros y un paralelo incremento de costos directos, precisamente en un momento en el que se necesitaba liquidez para industrializar la producción azucarera. En el apartado esclavitud e inversión de capital se habla del esclavo como parte de la inversión inicial, junto a la tierra y el equipamiento, esto es, se equipará a mano de obra al resto de bienes de capital. Se indica a continuación como este tipo de consideración de la mano de obra debería llevar a la inclusión de dicho coste contablemente como algo a amortizar.

Afirma igualmente Piqueras que los ingenios azucareros se administraron como el resto de las propiedades agrícolas y que no se incluía un cálculo de costes calculado correctamente y que analizase, cito textualmente, la productividad de las inversiones y la rentabilidad de la Hacienda o empresa.

Resulta interesante la descripción que hace de la forma en la cual se contabilizaba el valor del esclavo y como según la finalidad perseguida la mano de obra forzada era considerada y valorada de diferentes maneras, así mientras en unos casos se le asignaba el valor de mercado, en las escrituras de hipotecas prevalece el valor de garantía que se supone menor, hecho éste último que en opinión del autor reflejaba las diversas consideraciones que merecía el esclavo cuando se le considera como mercancía laboral o como activo incorporado a la explotación azucarera. En este sentido aporta como prueba la diferencia existente entre los precios de los esclavos según datos aportados por Laird Bergad o Mari Carmen Barcia y Fe Iglesias (Bergad, Barcia e Iglesias, 1995) y que explica por qué el primero trabajaba con los datos consignados en los protocolos notariales y la segunda lo hacía a través de los anuncios publicados en prensa que daban precios notablemente más altos. 
En un apartado posterior se hace referencia a los trabajos de Ramón de la Sagra referidos a las haciendas ganaderas en los que se habla de la imperfección del sistema contable o de información utilizado por los hacendados. Resulta curioso que en el mismo se hable de los gastos computados por la pérdida de fertilidad del terreno, el deterioro de los edificios o "la caducidad de los negros". En todo caso no parece que sea comparable la situación y las características de las Haciendas ganaderas con los Ingenios azucareros, al menos en lo que nos afecta y que es la consideración de la mano de obra forzada. Creemos que si bien al parecer en ambos casos en los registros de información contables utilizados se consideraba de alguna manera la depreciación de la mano de obra, en el caso de las haciendas ganaderas tiene sentido el considerar la mano de obra como una inversión a mucho más largo plazo, en el que factores tales como el nacimiento de nuevos esclavos pudieran en alguna medida compensar el envejecimiento de la mano de obra.

Se cita a continuación el trabajo de Francisco de Armas y Céspedes de 1866 en el que, basándose en los trabajos del naturalista Felipe Poey, se designaba para amortización anual el 2,5\% de pérdida de valor de los negros en cada año, lo que Armas amplió a 4,5\%. Sin embargo el autor dice que estos y otros trabajos posteriores que incluían la amortización de la mano de obra esclava hay que considerarlos más como un mecanismo de defensa ante la próxima, en aquel momento, abolición de la esclavitud y el deseo de los propietarios de ser resarcidos por la pérdida de la mano de obra forzada que como un sistema de información más objetivo y perfecto.

Para este autor en los ingenios el cálculo financiero era inexistente y considera que el único cálculo de naturaleza económica que se realizaba era a través del rendimiento medio de la caña y el precio del dulce tomados como bases para estimar el número esclavos sería necesario llevar para producir el azúcar, por considerarse que siempre había nuevas posibilidades de reutilización de dicha mano de obra.

\section{LA CONTABILIDAD DE LOS INGENIOS}

En el mundo de los ingenios azucareros parte del control y supervisión se ejercía mediante los registros e inventarios del patrimonio. De esta manera el registro de transacciones se convertía en un elemento base de rendición de cuentas a terceros (ya fueran estos los propietarios, los acreedores o también los compradores del producto final). La contabilidad se convertía así en el elemento de comunicación entre el ingenio propiamente dicho y todos los partnerships vinculados al mismo.

El tipo de registros que mayoritariamente se ha visto es el denominado de "entradas -salidas" más que el de la partida doble convencional. Es frecuente encontrar inventarios y actualizaciones de los mismos (altas y bajas), tanto de la 


\section{Santiago Garrido Buj}

mano de obra esclava como del ganado o de otros activos cualesquiera. Igualmente las personas vinculadas al ingenio se registraban en estados en los que se recogía no solamente su número sino también sus singularidades como pudieran ser edad, sexo, ocupación u otras características, contabilizándose también las altas y las bajas. Hemos visto pocos balances y cuentas de explotación convencionales referidas a los Ingenios e incluso a otros negocios colaterales a las explotaciones esclavistas, siendo además difícil la interpretación de los balances por la forma de presentación de los mismos

\section{Ilustración 1. Inventario de un ingenio ${ }^{14}$}
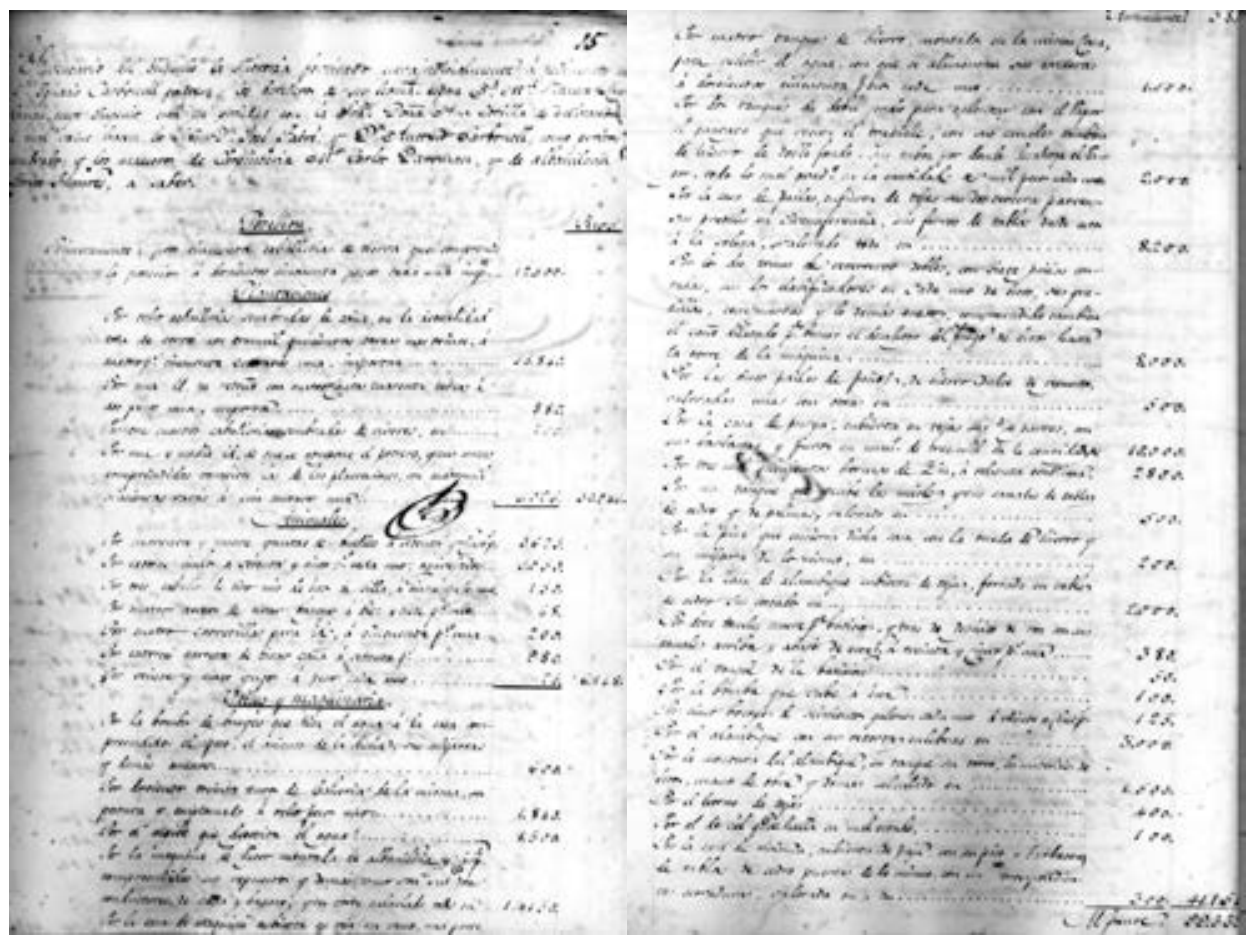

La contabilidad se convertía en el elemento clave del sistema de mayordomía pues como se ha dicho esta era la forma de control y vigilancia ${ }^{15}$. Sin embargo, a veces el control que se podía ejercer a través de estos registros de información era limitado pues estaban claramente separados los flujos monetarios de pagos y

${ }^{14}$ Todos los documentos insertados en el texto pertenecen a la colección del autor y pueden consultarse en la dirección URL www.docens.net.

${ }^{15}$ Higman Plantation in Jamaica, op.cit, pp. 4 y ss. 
cobros del resto de registros acerca de producción y costes. Por una parte se registraban datos contables de consumos e insumos pero vinculándolos a vales, recibos, pagarés y otros elementos similares. Por otra estarían los estados financieros de relación entre el ingenio y la banca en donde aparecerían cobros y pagos. En definitiva, el manejo del numerario estaba bastante alejado de la actividad de ese mayordomo que tantas funciones realizaba.

Hay otras dos características que hacen peculiar la contabilidad y registros de información en los ingenios con respecto a otros negocios. Estas son por una parte el largo período de maduración -un año- del ciclo productivo que hacía que solamente se cobrase una vez al año, esto es con la venta de la cosecha, mientras que los pagos se realizaban a través de todo el ejercicio. Como por otra parte en buena medida los recursos financieros precisos tales como el capital circulante eran suministrados y adelantados por los financieros y refaccionistas, a medida que se iban precisando, y estando todos ellos normalmente también involucrados en el proceso de venta y cobro de la producción, es muy posible que al final el hacendado y por tanto el ingenio exclusivamente recibiese el diferencial entre lo adelantado y lo cobrado por la producción, descontados los correspondientes márgenes y comisiones. A esto habría que sumar que el hacendado, aún sin estar físicamente en la plantación ni participar en el proceso productivo, "vivía" por cuenta del ingenio, convirtiéndose así sus gastos en un coste más para el ingenio, e igualmente descontándose del haber final de ingresos por la cosecha.

Para complicar aún más el proceso hay que pensar que unas personas tan involucradas en los resultados del negocio como eran este tipo de peculiares acreedores -agentes comercializadores-compradores del producto, no es de extrañar que participasen también de una manera más o menos intensa en el propio proceso de gestión del negocio, llevando sus propios registros y controles, en parte como forma de protección de su inversión.

Otra fuente de información sobre los registros eran los diarios de los mayordomos que, como se hacía en la España de los siglos anteriores entre terratenientes y administradores de sus fincas, registraban las cuentas "particulares" entre propietario y explotador. En ellos los mayordomos solían consignar cifras y estadísticas acerca de cosechas, activos, producción, etc.

El ingenio la Ninfa, propiedad de Francisco Arango es un buen ejemplo de la tecnificación de la gestión administrativa, así como del control de los rendimientos. Unos modelos de estadillos del citado ingenio, que patentizan dichos aspectos, los reproduce Manuel Moreno Fraginals en su obra El Ingenio (1972).

Por último, se presenta un estado de liquidación de cuentas de un ingenio embargado y en fase de liquidación, donde los registros de información contable y financiera se corresponden con el modelo de rendición de cuentas de la época. 
Ilustración 2. Rendición de cuentas de un administrador de ingenio (1876)
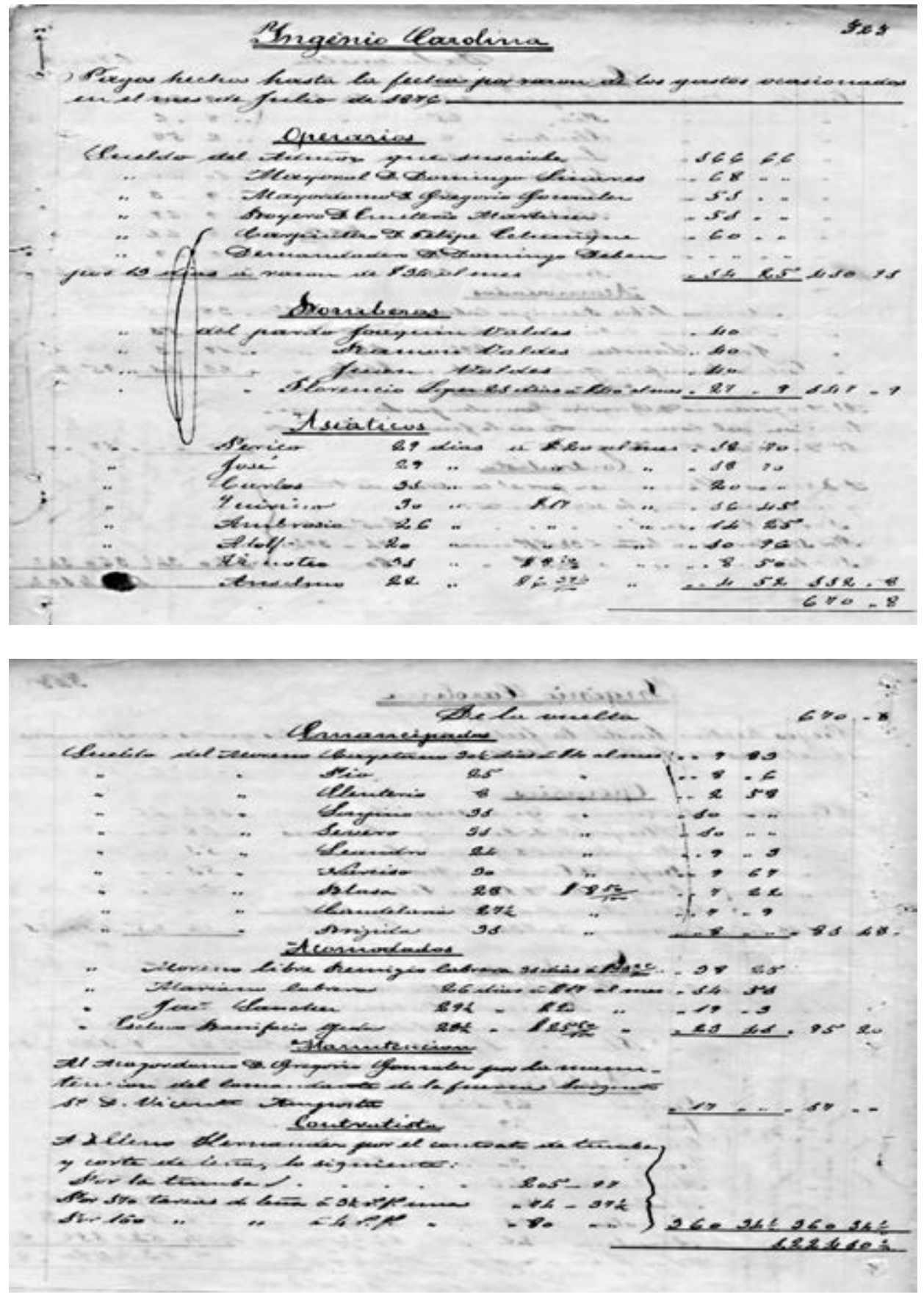

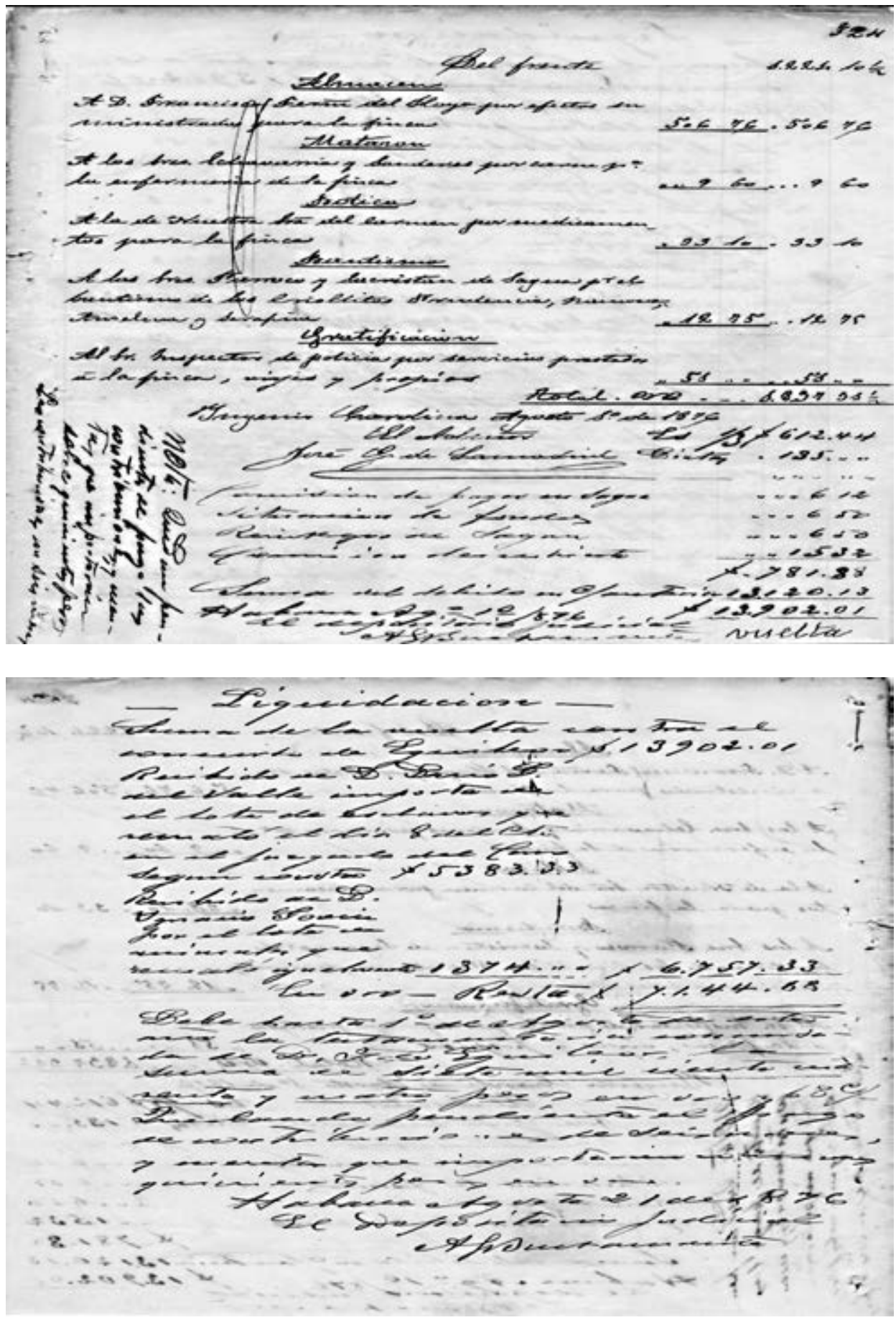

icade. Revista cuatrimestral de las Facultades de Derecho y Ciencias Económicas y Empresariales, $151-163$ $n^{\circ} 97$ enero-abril 2016, ISSN: 1889-7045 


\section{LA CONSOLIDACIÓN DE LAS PRÁCTICAS Y SU TRASPOSICIÓN Y FORMALIZACIÓN EN TEXTOS Y MANUALES}

Una buena forma de observar el grado de formalización de las prácticas de gestión y manejo de cualquier sector puede encontrarse en los manuales prácticos sobre la profesión u oficio o negocio correspondiente. Así por ejemplo para el caso de los ingenios azucareros con mano de obra esclava una forma de estudiar su gestión con un cierto grado de abstracción provendría del conocimiento y/o la existencia de textos formales y generalistas sobre dicha materia. Esta vía de análisis no conocemos que haya sido abordada, al menos como fuente primaria y básica, para el caso del azúcar cubano del siglo XIX.

Desde la óptica de empresa son muy limitados los trabajos que analizan la realidad de las plantaciones coloniales, si bien en los últimos tiempos están apareciendo algunos trabajos, sobre todo referidos al Caribe inglés y que se basan en los archivos de distintas haciendas y plantaciones conservados hasta el presente. Entre los clásicos destacan algunas instrucciones para las haciendas de los jesuitas y las instrucciones de algunos hacendados a sus hijos o administradores.

En la línea de los trabajos de Rafael Bivar (1997) ${ }^{16}$ acerca de esta misma metodología de investigación, y en su caso, referida al Brasil colonial, hemos tratado de encontrar trabajos que se refirieran a la gestión o administración de los ingenios azucareros en Cuba a lo largo de los siglos XVIII y XIX. La realidad es que es muy poco lo que hemos avanzado pues la mayoría de los trabajos que hemos podido localizar, tratan el tema de forma puntual o esporádica, además de que se encuentran entremezclados con prácticas genéricas de la agricultura, estudios de

\footnotetext{
${ }^{16}$ A administração do trabalho escravo nos manuais de fazendeiro do brasil império, 1830-1847 En este artículo de Rafael Bivar Marquese (1997) que recomendamos vivamente a los interesados en esta materia, se aborda el trabajo de los agricultores brasileños dedicados a estudiar las distintas formas de manejo de las plantaciones esclavistas brasileñas y en especial la forma de administrar la mano de obra esclava. Dichos trabajos son O Manual do Agricultor Brasileiro de Carlos Augusto Taunay, publicado originalmente en 1837, y la Memória sobre a Fundação de una Fazenda na Província do Rio de Janeiro, de Francisco Peixoto de Lacerda Werneck, publicado en 1847.

De hecho, desde principios del siglo XVIII existían importantes textos sobre la materia, que cabe diferenciar, como sugiere Bivar, en tres fases: Así la primera, estaría protagonizada por los jesuitas (en especial, los trabajos de Antonil y Benci) y abarcaría desde el siglo XVII hasta el siglo XVIII, con trabajos dedicados en buena medida a normalizar las relaciones entre amos y esclavos. Más tarde, en los siglos XVIII y principios del XIX, los autores olvidan el interés de los jesuitas, que deseaban: establecer reglas básicas para cambiar el comportamiento de los propietarios, apelando a que el gobierno de los esclavos debiera regirse por los principios cristianos, los autores de la ilustración dirigieron sus esfuerzos de forma preeminente a la búsqueda de un mayor rendimiento de las explotaciones, como se puede ver en las memorias de José Caetano Gomes, Manuel Arruda Camara y Luís dos Santos Vilhena.

Con posterioridad dice Bivar que el tema, de la gestión de los trabajadores esclavos cobró una especial importancia y que los autores de la época llegaron a desarrollar. una auténtica "teoría sobre la organización del trabajo esclavo".
} 
química y botánica y opiniones con un cierto contenido ideológico de alguno de los pensadores de la época, ya fueran estos pro esclavistas o no.

Paradójicamente, uno de los trabajos que describen con más precisión las explotaciones agroindustriales dedicadas al azúcar de caña cubano es el trabajo del obispo Díaz de Espada titulado Informe sobre diezmos que tomamos de los documentos sobre la esclavitud publicados en la obra Esclavitud y Sociedad (Torres-Cuevas y Reyes, 1986: 103-118). En el mismo comenzado en 1805 y datado en 1808, se da una descripción de los ingenios y por ende de su actividad sumamente pormenorizada. Así por ejemplo se consideran cuestiones tales como el agotamiento de las tierras o la deforestación del país, e igualmente cuestiona la utilidad de las grandes explotaciones con mano de obra esclava para el devenir del país.

Habla de cómo un ingenio de fabricar azúcar según las Ordenanzas municipales debe componerse al menos de 40 caballerías de tierra y de su coste que varía según su actitud para el cultivo y también de la cercanía a La Habana en razón de los costes de trasporte. Dice igualmente que

“...se requieren 50 esclavos de los que las tres cuartas partes deberán ser varones y piezas (que se llaman a los de 18 años arriba) y estos vale no y cada uno a 400 \$ hasta 450 \$ fuertes y las hembras valen lo mismo aunque pasen de esta edad. De las tierras se destinan 30 caballerías para caña y las 10 restantes al estilo del país para de esa o potrero donde se mantengan los bueyes y demás bestias de la y cargar que son de necesidad.

De estas mismas 10 caballerías se separa una parte para labor con la cual y con los claros que hay de un cañaveral a otro se mantienen de vianda toda la gente del ingenio y se concede a los negros lo que llaman conucos que es un pequeño espacio de tierra que les señala a cada 4,6 o 10 negros para que lo labren en beneficio suyo y puedan criar cualquier animal doméstico.

En las tierras que se destinan a sembrar caña y al todo del ingenio se siembra el PAN, que son los plátanos.

Siguen las fábricas cuyo costo es excesivo; y se reducen a casa de molienda, casas de purga, secadores, casa de vivienda con separación para los mayordomos y mayorales y para los criados y todos los operarios, enfermería, oratorio, tejar para construir las hormas de azúcar, para la losa y cubrir las casas, cuya extensión en las de artificio es de 200 a 300 varas.

Las maderas son de las más sólidas y de consiguiente caras y su conducción desde los montes donde se cortan costosísima. Los operarios de albañilería y carpintería si son meros peones, ganan seis reales diarios de salarios y si son oficiales desde un duro hasta tres, fuera de la manutención, según el mérito de cada uno.

La cal, la piedra en la arena hay que conducir la de otros terrenos o aumentan el número de caballerías que se compra, alguna que sean puramente pedregosa. 


\section{SAntiago Garrido Buj}

Todos los utensilios que pertenecen a la máquina de hierro o bronce, vienen de fuera del país, como grifos, tachos, pailas, calderas, machetes y hachas a un precio tan subido que regularmente el más ínfimo en el cobre es de tres o cuatro reales la libra

La caña se muele con bueyes y por lo menos ha de tener un ingenio 40 yuntas para moler, conducir la caña a los trapiches, acarrear la leña, todo el demás trabajo, porque hay muchos caballos y mulas; y su fortaleza no basta a mover las maquinarias ni a conducir de tanta distancia los utensilios.

Si el dueño no tiene potrero para mantener la boyada en el tiempo que no muele el ingenio que son seis meses, le cuesta pagar por la manutención de cada uno, un duro al mes, fuera del trabajo de conducirlos y el riesgo de los que le hurtan o se lisian o extravian..."

Los dos trabajos que se han encontrado de más relevancia son: en primer lugar, el de cómo administrar un ingenio de un autor que se autodenomina "un montuno" (Montuno, 1862) que pretende describir cómo fundar, construir y administrar ingenios; en segundo lugar, el de Administración de un ingenio de Antonio de Landa (Landa, 1866). Mientras el primero es un trabajo que abarca múltiples cuestiones que van desde la elección del terreno o el tipo de caña a la siembra, pasando por la selección y control de la mano de obra esclava y terminando con los aspectos tecnológicos del proceso de manufactura de la caña; el segundo es más de opinión y contiene interesantes reflexiones acerca del modo de tratar a la mano de obra entre otras cuestiones ${ }^{17}$.

El primero de los trabajos referenciados se denomina Cartilla práctica del manejo de ingenios o fincas destinadas a producir azúcar, está publicado en Irún en 1802.

Tras un prólogo en el que se simulan preguntas y respuestas entre el autor y un hacendado en el cual se preguntan por qué no existen en la Isla manuales prácticos sobre cómo administrar los ingenios y producir azúcar, y de ahí su interés en publicar una obra práctica a este respecto. Resulta interesante la defensa del trabajo del administrador como una función técnica aprendida en la práctica cotidiana y convertida en un saber y un oficio que el autor reivindica.

${ }^{17}$ El resto de trabajos que han visto están bastante menos centrados en el aspecto que nos interesa, esto es, las cuestiones relacionadas con la función de gestión. Destacamos entre ellos los de Francisco Frías y Jacott, conde de Pozos Dulces y los de su hermano José Frias; en segundo lugar los de Francisco F. Ibáñez (conde de Ibáñez) sobre los pequeños ingenios); los del botánico Juan Poey en lo que se refieren al azúcar y también los de Juan Bautista Jiménez quien sobre todo con referencia a Santa Clara elaboró una serie de trabajos que en buena medida tocan la caña dentro de otros cultivos agrícolas así por ejemplo sus obras "Aventuras de un mayoral", "Los esclavos blancos", o "La colonia". Este autor igualmente dirigió revistas como la denominada "El agricultor práctico" publicada en 1899 en Santa Clara. También existen interesantes comentarios en la obra de Ramón de la Sagra o en el trabajo del gobernador militar de Matanzas Cecilio Ayllón sobre la construcción de barracones en los ingenios (ordenó sustituir todos los bohíos por construcciones de obra). 
La obra de este autor tiene aproximadamente 120 páginas en las que se hace un recorrido bastante exhaustivo de las distintas actividades y trabajos llevados a cabo en un ingenio. La simple enumeración de los capítulos de la misma da una idea de la amplitud del trabajo, así se comienza hablando de la adquisición de tierras y de la calidad y cantidad necesaria, para pasar al diseño de la explotación describiendo la ubicación óptima del batey, el guarda rayas y los cañaverales así como las zanjas y desagües.

Se continúa hablando de las clases de caña y de las labores agrícolas como son la siembra el arado el chapeo y el abonado, para pasar después a la enumeración y descripción de los recursos necesarios en cuanto a fuerza de trabajo esclava, y animales de carga y tiro.

Trata después la tarea de la zafra incluyendo el corte de la caña y el transporte de la misma así como la descripción de las casas del ingenio, calderas, y purga.

En la segunda parte del trabajo se abordan las cuestiones organizativas que más nos interesan, así y comenzando con unas nociones sobre construcción para el administrador, se habla de los libros contables que debe llevar todo administrador de ingenio así como de las funciones de vigilancia y de los horarios de trabajo. A continuación se aborda la cuestión de la alimentación, el vestido y el alojamiento, y también los aspectos relativos a la enfermería y a la guardería de los recién nacidos.

Por último se incluye un apartado referente a la moralidad y otro a los castigos y protección de la mano de obra esclava. Y, para terminar, se abordan algunas cuestiones menores como son la recepción y entrega de las mercancías y también la posibilidad de subcontratar trabajos.

En suma se trata una obra en la que se hace una descripción muy pormenorizada y sumamente detallada del trabajo que realiza el administrador de un Ingenio desde la óptica de la praxis cotidiana.

La obra de Antonio de Landa que lleva como título El administrador de Ingenio va acompañada de un subtítulo que dice: Instrucción para gobernar bien y dirigir los trabajos de un Ingenio o finca donde se elabora azúcar, con la explicación de un nuevo sistema de molienda y los deberes e instrucciones para los mayordomos, mayorales, enfermeros, boyeros, carreteros y demás empleados. Bajo este pomposo título muy al estilo de los de la época y similar al de las denominadas cartillas técnicas elaboradas fundamentalmente para el sector agrario, el autor desgrana una serie de ideas acerca de cómo administrar un ingenio de las que quisiéramos destacar las siguientes consideraciones.

En primer lugar se trata de una obra atípica por cuanto abarca una pluralidad de aspectos que van desde cuestiones relacionadas con la dirección de personal hasta auténticos principios de administración, pasando por cuestiones técnicas como pueden ser las referidas a la planta o caña de azúcar o a los sistemas de procesado o purgado. 


\section{Santiago Garrido BuJ}

En segundo lugar es llamativo el desglose y diseño de funciones para cada uno de los eventuales gerentes y "mandos intermedios" a cargo del ingeniero, definiéndose en cada caso la relaciones de cada uno de estos puestos subalternos con sus superiores e inferiores.

Por último es de destacar la clara separación que se hace entre propiedad y administración, al estilo de lo que en años posteriores comenzó a ser una realidad quizás el caso del azúcar cubano, con unos propietarios en la mayoría de los casos absentistas, explica esta clara división entre propiedad y gestión y como, para el autor, el papel del administrador de un ingenio es concebido como un auténtico trabajo de gestor o manager con derechos y obligaciones frente a la propiedad ${ }^{18 .}$

La obra de pequeño formato (63 páginas más índice y una página más de notas) se estructura en tres partes dedicadas: la primera a los "derechos, reglas y observaciones respecto de los deberes del encargado o administración del Ingenio de elaborar azúcar" que a su vez contiene 15 capítulos; una segunda parte dedicada a las "observaciones y reglas respecto de los deberes del mayoral, el boyero, carretero, enfermero y otros" que se estructura a su vez en nueve capítulos; y una tercera parte en la que se habla de "observaciones respecto de los deberes e instrucción del mayordomo” que contiene seis capítulos más.

La primera parte, en nuestra opinión la más interesante, entremezcla principios generales de administración y reflexiones sobre las cualidades que debe de tener el administrador, con los modos en que debe de obrar y organizar el trabajo. Quizás una descripción genérica de los capítulos que contiene pudiera dar una idea del alcance del trabajo así se habla de:

- El ascendiente o predominio.

- La inteligencia.

- La justicia.

- Castigo, premio y protección.

- Privaciones y castigos.

- De los padrinazgos.

- Horas de descanso y días de fiesta.

- Nuevo sistema de molienda.

- Moral y religión.

- Alimentos y bebidas, reglas de higiene, precauciones y vestuario.

- Economía.

- Las clases de caña, siembras, abonos y precauciones para conservar los cañaverales.

- De incendios.

${ }^{18}$ Frente a otros trabajos en los que el papel del administrador del ingenio es el de "persona para todo" entremezclándose sus tareas con las de los técnicos en el azúcar (maestros del azúcar), los mayorales; y los mayordomos. 
- El respeto y buena voluntad de los empleados u operarios.

- Las rivalidades entre operarios.

A nuestro entender son de destacar varias cuestiones que dan al trabajo su principal valor. En primer lugar se hace una clara distinción entre el mayordomo y otros trabajos que en el ingenio pueden estar ejercidos, bien por personas libres contratadas a las que se denomina "operarios" o bien por mano de obra esclava. Es en nuestra opinión esta distinción una clara percepción de la necesidad de un organigrama laboral estructurado y de una diversificación de tareas y funciones que se verán en los siguientes apartados.

Una segunda cuestión que nos parece interesante es como se hace alusión a principios tales como la delegación de responsabilidades o la incardinación de cada tarea en el conjunto. Igualmente son de destacar las alusiones a ámbitos tan separados como la religión ${ }^{19}$; la alimentación o la higiene; la economía o los aspectos relacionados con el propio trabajo o las labores agrícolas.

En tercer lugar presenta una singularidad el capítulo que el autor denomina "Nuevo sistema de molienda". En el mismo se describe, no una nueva técnica para moler sino una programación de la misma por tareas semanales en la que se combinan las necesidades del ingenio en cuanto a la rapidez en la molturación para evitar el secado y consiguiente pérdida de jugo de la caña, y la disponibilidad de mano de obra, de tal modo que el excesivo agotamiento no produzca errores y accidentes, que genere un sistema por el contrario eficaz en cuanto a resultados, conservando los tiempos de descanso necesarios. Vemos que en esta explicación, basada en la práctica y que se combina con los tiempos de descanso, un buen análisis sistemático de las tareas a realizar y de los condicionantes del proceso técnico, que bien pudiéramos equiparar a similares análisis de tiempos y movimientos próximos a la dirección científica del trabajo.

Por último en relación con este apartado resulta singular, al menos no conocemos ninguna otra referencia similar en trabajos sobre administración de los ingenios, lo que el autor denomina el "padrinazgo", que consiste en síntesis en la utilización de un intermediario o valedor del esclavo que realizaba tareas de cierta importancia, cuando este último tenía, bien algún fallo en su trabajo bien algún accidente laboral que producía efectos en la producción. El sistema, en palabras del autor, consistía en que... cuando un esclavo incurre en una falta, bien por desobe-

\footnotetext{
${ }^{19}$ Conviene recordar como en el caso cubano dadas las connotaciones religiosas del papel colonial de la metrópoli, existían una serie de obligaciones con respecto a la educación moral de los trabajadores que por su obligatoriedad condicionaban los modos de trabajo y que era necesario tener en cuenta en la programación de actividades, toda vez que cuestiones como los bautizos tenían el carácter de obligatorio, no para los padres sino para el dueño del esclavo, y otros como el matrimonio podía llevar a que el esclavo cambiase de dueño. Igualmente las obligaciones de educación religiosa y de descansos para la oración y en las denominadas fiestas de guardar condicionaban todo un modelo socio-religioso que era preciso considerar en la planificación empresarial.
} 


\section{Santiago Garrido Buj}

diencia, falta de horas en el trabajo o por haber resultado algún lance desagradable, como si se es carretero y se le muere, manca o descarga un buey por falta de precaución, o al pasar por un río o arroyo crecido la corriente arrastra la carreta arrollando los bueyes... Convencido de su falta va a buscar un padrino antes de avisarle al mayoral o administrador lo acaecido porque teme, y se presenta con su padrino, siendo este un hombre de consideración, por su juicio o posición social, y ruega que no se le castigue al esclavo por aquella vez, pues que le ha sucedido o faltado sin haberlo podido remediar y sin intención según se corrige por la relación que le ha hecho... Esta singular figura del padrino que por otra parte vemos que sólo cabe utilizarse en el caso de fallo fortuito, permite "racionalizar" en alguna medida el hecho acaecido, dando al esclavo una posibilidad de defensa mediante la intermediación y objetivando, en la medida de lo posible, el hecho y por tanto la eventual sanción o amonestación. Difícilmente un responsable de personal, ya sea el mayordomo, el mayoral o el capataz, conseguirá con posterioridad un respeto basado en la equidad si, como indica la autor una vez marchado el padrino se hace caso omiso de sus recomendaciones ${ }^{20}$.

En cuanto a la segunda parte solamente cabe destacar la pormenorización de tareas para cada una de las funciones a llevar a cabo en el complejo sistema agroindustrial de la elaboración de azúcar, mostrando una visión global del proceso y un detalle para cada una de las operaciones. En nuestra opinión solamente un claro conocimiento de cada una de las tareas y funciones permite una efectiva y exitosa división del trabajo.

Sin entrar en mayores detalles si queremos destacar en la tercera parte del trabajo el apartado dedicado a la contabilidad por contener una explicación de cómo se llevaba a cabo la misma en los ingenios azucareros. Así el autor habla de varios libros en los que anotar las siguientes cuestiones o aspectos:

- Control de producción, existencias y activos: anotación de las carretadas de caña diarias, molienda y guarapo cada 24 horas.... Igualmente la entrada diaria de panes de azúcar en la casa de purgas, bocoyes de mascabado que se llenan... Se trata de un claro control de la producción que permitirá con posterioridad y de forma diaria monitorizar el proceso y detectar irregularidades). Igualmente se habla de incluir en este libro otros aspectos que entendemos no deberían estar juntos como la compra de provisiones y la obra que se recibe. Esta gran cantidad de información en un solo libro parece que más que un mero inventario y control de la producción es un libro de cuentas entre el administrador y el propietario.

- Control de salarios. Un segundo libro del que se habla es un libro de cuentas corrientes para los operarios para conocer las relaciones con los mismos, los posibles anticipos que se les hubiesen podido pagar y la gestión de sus salarios.

\footnotetext{
${ }^{20}$ Creemos que esta institución sui generis es también, desde la óptica empresarial, un excelente sistema de análisis de desviaciones.
} 
- Cuentas con terceros. Un tercer libro para llevar las cuentas corrientes de otros con quienes se tengan negocios que se indica también podría estar junto con el de pago a los operarios o contratas.

- Inventarios de personal y animales. Un libro más que debe anotar la dotación de trabajadores, boyada y demás animales; los trabajadores que nacieron y fallecieron los prófugos etcétera. Este es el libro a modo de inventario del que más manuscritos hemos encontrado y que de alguna manera parece ser el documento mediante el cual el Ingenio atestiguaba el valor de sus medios productivos, con vistas ya fuere a su posible venta, al alquiler del mismo o simplemente de la mano de obra y también a efectos de herencias. Se incluye a continuación un ejemplo del mismo. En cualquier caso es más habitual encontrar relaciones de todo el personal del ingenio (incluido el contratado y los administradores) que aquellos que incluyen animales y otros activos.

Igualmente se habla de formar estados semanales de la producción, así como de las tareas relacionadas con la firma de partes, oficios, recibos, licencias, vales etcétera. Además se habla de cómo debe de existir un inventario general que cada administrador, al hacerse cargo de un ingenio, debe solicitar y evaluar para ver aquello de lo que se hace cargo y si su antecesor en el cargo realmente había conservado lo que dicho inventario dice.

En suma se trata de un trabajo de gran alcance en el que el análisis sistemático de tareas así como la gran dedicación a las relaciones humanas en lo que respecta tanto a los operarios, mandos intermedios, cómo y sobre todo a los esclavos convierten el manual en un trabajo en el que se atisban algunos de los principios pocos años después formulados y sistematizados en trabajos como los de F. W. Taylor o Henry Fayol. El complejo agroindustrial del azúcar se convierte así por su complejidad en una explotación que requiere de un análisis sistemático y coordinado de todas sus tareas. Esta consideración sistémica, así como las referencias a principios como la delegación de tareas o el trato al personal hacen de este tipo de trabajo un excelente argumento en contra de quienes durante muchos años negaron el papel del management en las explotaciones esclavistas del siglo XIX.

Los trabajos anteriores son comparables a los encontrados en México tales como el llamado Cuaderno curioso para maestros purgadores (Anónimo, 1759), o las instrucciones dadas por el capitán José Rincón a su hijo para la administración de su Hacienda (Rincón, 2005). Igualmente existe una pluralidad de instrucciones dadas para el manejo de las haciendas de la Compañía de Jesús en el nuevo mundo ${ }^{21}$. En todos los casos se mezclan consejos cercanos a la praxis y basados en

\footnotetext{
${ }^{21}$ Véase por ejemplo el artículo de Jorge Troisi (2004) o también el de Carlos Page (2008).
} 
la experiencia, con opiniones y "filosofías" propias de la época y que nada aportan al gobierno de las explotaciones.

Merecen igualmente citarse en este apartado los trabajos realizados por el denominado Circulo de Hacendados de la Isla de Cuba, destinados sobre todo a divulgar los progresos en el campo de la agricultura científica y que en buena medida se plasmaron en su publicación denominada Revista de agricultura destinada a difundir los avances en la materia y en la creación en 1881 de la Escuela de agricultura de la Isla de Cuba.

Si uno observa los trabajos que sobre la administración de ingenios existen, sobre todo con referencia al Caribe inglés (Jamaica, Barbados, Trinidad, ....) y a los EE. UU., parece constatarse la formación de unos ciertos "códigos de buenas prácticas" en relación con la forma de administrar plantaciones. En la misma línea creemos que los trabajos referenciados con respecto a Cuba son también el reflejo de una práctica habitual y de unos hábitos consuetudinarios convertidos en auténticas reglas acerca de cómo manejar los ingenios azucareros.

En otro orden de cosas hay un cierto número de trabajos cubanos que en alguna medida también pueden considerarse como "manuales" de administración de explotaciones azucareras, así los trabajos de Troncoso, Zayas e incluso el de Cecilio Rincón, aunque solamente en parte se refieren a tareas de Administración, contienen también interesantes observaciones sobre el modo de gestionar considerado adecuado en la época. Los hacendados de la época estaban interesados por los avances e incluso ofrecían sus fincas para efectuar experimentos y pruebas y como dice Antonio Bachiller y Morales en cita que tomamos de Leida Fernández (Fernández Prieto, 2000) “...aconseja, dirige y lee lo que se publica y recomienda; que no reprueba lo que escriben los autores porque no son labradores prácticos; sino que comprende que condes y abogados, médicos y literatos no hacen más que recoger lo recomendado por la práctica de especialistas distinguidos que no aspiran a una originalidad imposible."

Una diferencia entre los trabajos o textos cubanos y otros como los del Brasil o de los EE. UU. es que en los primeros no aparecen, por lo general, rasgos de paternalismo por ninguna parte. Los textos cubanos son, en ese sentido, asépticos y no entran para nada en consideraciones morales, ni en el interés del buen tratamiento en aras de mayores rentabilidades. Tampoco suelen aparecer, como en la literatura de EE. UU., alusiones del interés público en "socializar" a los negros para integrarlos en la sociedad. Sobre este particular puede verse por ejemplo el trabajo de Bivar (1997) o también Bivar, Feitores do corpo, Misionarios de mente Senhores, letrados e o controle dos escravos nas Américas, 1660-1860 (2004).

Igualmente en los trabajos de Francisco Frías y Jacott (conde de Pozos Dulces) existen interesantes reflexiones acerca de las ventajas del trabajo en pequeñas explotaciones de productores de caña e independientes y sobre todo del interés de su separación de los ingenios manufactureros. 


\section{LA ADMINISTRACIÓN DE LAS PLANTACIONES EN EL CARIBE INGLÉS Y EN LOS EE. UU.}

Aunque no sean propiamente objeto de este trabajo, las plantaciones esclavistas del sur de los EE. UU. con anterioridad a la guerra civil, y sobre todo los del Caribe inglés y también francés, son junto con los trabajos del Brasil colonial un buen referente sobre la forma de gestión de las explotaciones que utilizaban mano de obra esclava en el siglo XIX. La similitud de sus producciones así como el área geográfica en el que operaban y también la coincidencia en el tiempo y en consecuencia con los desarrollos técnicos y de gestión de la época, hacen que un análisis de los trabajos en estos otros países puedan servir para el caso cubano, máxime cuando sobre todo en este último caso los trabajos son muy limitados.

Se analizan sobre todo los trabajos del Caribe inglés por ser los más documentados en cuanto al objeto que nos ocupa y donde la separación entre propietarios y administradores hacía que los registros tanto de operaciones, de resultados fuesen exhaustivos y sistemáticos además de formalizarse documentalmente.

La literatura clásica ha prestado poca atención al trabajo esclavo no considerándose en la mayoría de los casos su gestión o administración como una tarea de dirección, sin embargo la asignación de tareas y las rutinas de trabajo necesarias con dicho tipo de mano de obra hacen pensar en un modelo racional y estructurado de gestión de los recursos humanos, cuando menos similar en desarrollo y profundidad a los de la mano de obra libre.

Como indica Justin Roberts (2008) en su tesis doctoral acerca de las estrategias de gestión en el Caribe y el sur de los EE. UU. en los finales del siglo XVIII y principios del XIX, a partir de la segunda mitad del siglo XVIII los plantadores caribeños empiezan a buscar el incremento de la eficiencia de las plantaciones por dos vías, a saber: la mejora de las condiciones laborales, y la consideración de las explotaciones como un sistema que debía monitorizarse y controlarse, y que estaba abierto a la innovación. El trabajo de los plantadores se convierte de esta manera en un oficio especializado que requiere formación, entrenamiento práctico y experiencia así como dedicación y compromiso.

Todo lo anterior lleva a que en el siglo XIX el trabajo de los gestores de las plantaciones pueda ser llamado o considerado como un auténtico Scientific management ${ }^{22}$. El administrador se configura como el "alma" de la plantación esclavista moderna (en nuestro caso del Ingenio azucarero) y es quien a través de su tarea y dedicación convierte a la explotación en un auténtico sistema organizado irracionalmente estructurado, además de en un modelo y proceso productivo eficaz y eficiente.

Estas ideas de la necesidad de tratar sistemáticamente las operaciones de gestión de las explotaciones esclavistas las encontramos en muchos trabajos de la

\footnotetext{
${ }^{22}$ Véase Roberts, op.cit., pp.30 y ss.
} 


\section{SAntiago Garrido Buj}

época incluso en los escritos de George Washington quien en las instrucciones al administrador de su plantación llamado James Anderson le insiste en cómo debe hacer su trabajo guiándose por normas e instrucciones planificadas, ya que como dice textualmente "in everything ... system is essential to carry on business well and with ease", que eran auténticos administradores.

Igualmente se repite esta reflexión en el manual publicado en 1786 Instrucciones para el manejo de una plantación en Barbados y para el tratamiento de los negros citado igualmente por Justin, en donde se insiste en como "Men who manage without system... must ever remain subject to the disappointment and failure wich so many experience."

Durante la época que nos ocupa los deseos de racionalización de los procesos productivos fueron constantes y aunque las mejores prácticas tardaron en implementarse, las mejoras singulares aunque no fueran grandes, sí fueron muchas y que basándose ya fuera en la praxis, la observación o en la innovación y la copia de otros modelos (en buena medida técnicas procedentes de Europa), produjeron buenos resultados. Así pequeñas variaciones en las formas de cultivo, la gestión del trabajo, en las técnicas de contabilidad con el manejo de los animales, unidas a mejoras en la herramienta o en la calidad de la misma llevaron a unos resultados que por ejemplo para el caso de Barbados algunos cifran en un incremento del output por esclavo de un 35\% entre 1750 y 1834.

Parece que algunas técnicas tardaron más tiempo en implantarse debido a la creencia de que el negro esclavo no sería capaz de aprender las nuevas técnicas o de realizar trabajos especializados, pero en nuestra opinión más que una falta de creencia en la capacidad del esclavo, lo que los plantadores estaban barajando era la necesidad de cambiar de un tipo de trabajador orientado a tareas básicas y sumamente sencillas por otro más especializado y en alguna medida similar a la mano de obra libre.

Queremos decir que quizá no fue tanto la creencia en la falta de capacidad de aprendizaje del trabajador esclavo, sino más bien su consideración precisamente de esclavo, lo que llevaba a su utilización como elemento motriz o de trabajos sumamente sencillos con la posibilidad de intercambio de tareas entre toda la dotación y con escasa necesidad de habilidades específicas para conseguir resultados óptimos. Dicho de otra manera un trabajo especializado y cuyo resultado sea función de la habilidad desarrollada no parece que sea el mejor para ser ejercido por alguien carente de motivación y considerado como un elemento material más de la producción que se sustituye cuando se agota como fuerza laboral.

\section{BIBLIOGRAFIA}

ANÓNIMO (1759), Quaderno curioso, y practica de purgadores. Dedicalo al Gmo. Sr. Sn. Josep, Biblioteca Universidad Veracruzana, Morelos: Yngenio Xochimancas. 
AUFHAUSER, R. K. (1973), "Slavery and Scientific Management", The Journal of Economic History, vol. 33, núm. 4, pp. 811-824.

BERGAD, L., BARCIA, M. C., \& IGLESIAS, F. (1995), The Cuban Slave Market 1780-1880 (Vol. 79), Cambridge University Press, New York.

BIVAR, R. (1997), "A administração do trabalho escravo nos manuais de fazendeiro do Brasil Império, 1830-1847”, Revista de Historia, diciembre, pp. 95-111.

BIVAR, R. (2004), Feitores do corpo, Misionarios de mente Senhores, letrados e o controle dos escravos nas Américas, 1660-1860, Companhia das Letras, Sao Paulo.

CHANDLER, A. (1965), The Raildoads: The Nation's Big Business, Harcourt Publ, New York.

CHANDLER, A. (1977), The Visible Hand: The Managerial Revolution in American Business, Harvard University Press, Cambridge.

CHANDLER, A. J. (1990), Scale and Scope. The Dynamics of Industrial Capitalism, Harvard University Press, Cambridge.

COOKE, B. (2003), "The Denial of Slavery in Management Studies", Journal of Management Sudies, núm. 40, pp. 1895-1918.

ELY, R. T. (1961), Comerciantes Cubanos del siglo XIX, Libreria Martí, Habana.

FERNÁNDEZ PRIETO, L. (2000), "La Agricultura Cubana a fines del siglo XIX: Ciencia y Economía", Congreso de Americanistas, pp. 422 a 434.

FOGEL, W., \& ENGERMAN, R. (1981), Tiempo en la Cruz, Siglo XXI editores, Madrid.

HIGMAN, B. W. (2005), Plantation Jamaica, 1750-1850: Capital and Control in a Colonial Economy, University of the West Indies Press, Kingston.

LANDA, A. d. (1866), El Administrador de Ingenio, La Fortuna, La Habana.

MONTUNO, U. (1862), Cartilla práctica del manejo de ingenios ó fincas destinadas a producir azúcar escrita por Un Montuno, Imp. de la Elegancia, Irún.

MORENO, M. (1972), El Ingenio, Crítica, Barcelona.

PIQUERAS, J. A. (2002), "El capital emancipado. Esclavitud, industria azucarera y abolición en Cuba" en Piqueras Arenas, J. A. (comp.), Azúcar y esclavitud en el final del trabajo forzado, Fondo de Cultura Económica, Madrid, pp. 241-251.

RINCÓN, J. (2005), "Memoria de José Rincón Gallardo 1704", Relaciones, vol. XXVI, pp. 130-160.

ROBERTS, J. (2008), Sunp to sundown: Plantation managenent strategies and slave work rouitines in Barbados, Jamaica and Virginia 1776-1810, UMI Disertation Publishing, Baltimore.

TAYLOR, F. (1911), Principles of Scientific Management, Harper\& Brothers, New York.

TORRES-CUEVAS, E., \& REYES, E. (1986), Esclavitud y Sociedad; Notas y documentos pra la historia de la esclavitud negra en Cuba, Ciencias Sociales, Habana. 